\title{
The role of modeling towards impacting quality education
}

\author{
Abdullahi Salisu' ${ }^{1}$, Emmanuel N. Ransom ${ }^{2}$ \\ ${ }^{1}$ Department of Surveying \& Geo-Informatics, The Federal Polytechnic, Bauchi, Nigeria \\ ${ }^{2}$ Department of General Studies Education, Federal College of Education, Pankshin, Nigeria
}

\begin{abstract}
The study examines several models of teaching and learning, the roles of modeling techniques in teaching and learning, and the benefit of modeling techniques; it also gives a demonstration and explanation of modeling technique in children learning.
\end{abstract}

Keywords: education; modeling techniques; teaching; learning

\section{INTRODUCTION}

Modeling is an instructional strategy in which the teacher demonstrates a new concept or approach to learning and students learn by observing. Modeling describes the process of learning or acquiring new information, skills, or behavior through observation, rather than through direct experience or trial-and-error efforts. Learning is viewed as a function of observation, rather than direct experience (Holland \& Kobasigawa, 1980). Research has showed that modeling is an effective instructional strategy in that it allows students to observe the teacher's thought processes. Using this type of instruction, teachers engage students in imitation of particular behaviors that encourage learning. Learning would be exceedingly laborious, not to mention hazardous, if people had to rely solely on the effects of their own actions to inform them on what to do. Fortunately, most human behavior is learned observationally through modeling: from observing others, one forms an idea of how new behaviors are performed, and on later occasions this coded information serves as a guide for action Bandura (1986). Modeling can be used across disciplines and in all grade and ability level classrooms.

\section{MODELING AS A MODE FOR LEARNING}

Modeling is one of the most efficient modes of learning of any new skill or knowledge (Bandura, 1986). It is difficult to imagine any society that has not relied on models in one form or another to transmit the most important and basic cultural values, customs and beliefs from one generation to the next. If all of human learning had occurred at the level of direct experience or trial-and-error efforts, human progress would have occurred at a much slower rate. From childhood through adulthood, modeling plays a key role in the acquisition and 
development of cognitive and meta-cognitive skills, fine motor skills, interpersonal skills, and later professional skills. Each of these is gained primarily through the process of observation. Motor skill acquisition and development occur as children observe parents, siblings, and peers interact with their worlds. From the simplest act of learning how to pick up and use a fork to the complex and multifaceted process of driving a car, all of these skills are acquired through the observation of models. Which skills are learned and repeated by the observer will ultimately depend upon the types of reinforcement received, as well as how capable or motivated the observer is to repeat those behaviors.

Learning simple cognitive skills, such as basic arithmetic or reading skills, as well as more complex cognitive skills, such as critical thinking or problem solving, are facilitated when models verbalize their own thought processes as they engage in these activities. Thoughts are thus made observable, and potentially modeled, through overt verbal representation of the model's actions. Modeling both thoughts and actions has several helpful features that contribute to its effectiveness in producing lasting improvements in cognitive skills.

Nonverbal modeling gains and holds attention, which is often difficult to sustain by talk alone. It also provides an informative semantic context within which to imbed verbalized rules. Behavioral referents confer meaning on cognitive abstractions. Moreover, verbalized rules and strategies can be reiterated in variant forms as often as needed to impart a cognitive skill without taxing observers' interest by using different exemplars. In addition, the more and varied application can deepen understanding of generative rules.

According to the social cognitive model of learning, the acquisition of meta-cognitive and self-regulatory skills and competence first develops through social interaction, otherwise known as observational learning (Schunk \& Zimmerman, 1996). Schunk and Zimmerman suggest that in developing what they call self-regulatory competence, students need to be given opportunities to practice the various strategies associated with self-regulated learning in order to fully develop and master this set of skills. Mastering these skills is made easier when models provide "guidance, feedback, and social reinforcement during practice."

\section{TYPES OF MODELING}

\section{1. Disposition modeling}

In disposition modeling, teachers and students convey personal values or ways of thinking. Although teachers must be careful not to offend and to be inclusive when modeling dispositions, this type of modeling is important for facilitating the development of character and community. Teachers can model desired personal characteristics by acting with integrity and empathy and by setting high expectations. Teachers who are creative, diligent, wellprepared, and organized model the kinds of strategies needed to succeed in the workforce.

\section{2. Task and performance modeling}

Task modeling occurs when the teacher demonstrates a task students will be expected to do on their own. This type of modeling generally precedes activities like science experiments, foreign language communication, physical education tasks, and solving mathematical equations. This strategy is used so that students can first observe what is expected of them, and so that they feel more comfortable in engaging in a new assignment. 


\section{3. Meta-cognitive modeling}

Meta-cognitive modeling demonstrates how to think in lessons that focus on interpreting information and data, analyzing statements, and making conclusions about what has been learned. This type of modeling is particularly useful in a math class when teachers go through multiple steps to solve a problem. In this type of modeling teachers talk through their thought process while they do the problem on the board or overhead. This thinking-outloud approach, in which the teacher plans and then explicitly articulates the underlying thinking process, should be the focus of teacher talk. This type of modeling can also be done in a reading class while the teacher asks rhetorical questions or makes comments about how to anticipate what is coming next in a story.

\section{4. Modeling as a scaffolding technique}

When using modeling as a scaffolding technique, teachers must consider students position in the learning process. Teachers first model the task for students, and then students begin the assigned task and work through the task at their own pace. In order to provide a supportive learning environment for students who have learning disabilities or English language learners, teachers will model the task multiple times.

\section{5. Student-centered modeling}

Teachers can often call on students to model expected behaviors or thought processes. In student-centered modeling, teachers engage students who have mastered specific concepts or learning outcomes in the task of modeling for their peers. This type of modeling makes the class less teacher-centered, which in some cases provides a more supportive learning environment for students.

\section{6. Benefit of Modeling, Demonstration, and Explanation to Children}

All children need instruction, but some children need substantial amounts of truly highquality teaching to learn to read and write alongside their peers. What all children need, and some need more of, is models, explanations, and demonstrations of how reading is accomplished. What most do not need are more assignments without teacher-directed instruction, yet much of the work children do in school is not accompanied by any sort of instructional interaction or demonstration.

Children are routinely asked questions after reading but are infrequently provided with demonstrations of the comprehension strategies needed to answer the questions posed. In short, too often assigning and asking are confused with teaching. When the teacher-directed instructional component is left out of the lesson, it enormously reduces the potential of many activities (e.g., maps, webs, summary writing, response journals) for supporting the acquisition of complex comprehension strategies (Fielding \& Pearson, 1994; Pressley, 2006). With no clear instruction, children are left to discover the strategies and processes so important to skillful readers and writers. Some children puzzle through the activities assigned but never discover the thinking patterns that proficient readers use.

Modeling, explaining, and demonstrating are essential teaching activities if all children are to learn to read and write. Teachers model the reading and writing processes by engaging 
in them while children observe. Reading aloud to children, for instance, provides a model of how reading sounds and how stories go. Composing a list of things needed for a project provides a model of one function of writing. Talking about how a newspaper story made us worry provides a model of response to text. Models are essential, but models do not give children much in the way of information about how proficient readers actually accomplish such feats.

Reading aloud to children is one way to model fluent reading and thoughtful talk about books, stories, and responses. While read-alouds have become increasingly popular, research indicates that nearly one-third of classroom teachers rarely read children's books aloud to their students (Hoffman, Roser, \& Battle, 1993). They also offer guidelines for read-alouds:

- Designate a time each day for reading aloud, not a time-filler slot.

- Select quality literature to read.

- Discuss the books read with children.

- Create groups for children to share responses to books read.

- Reread selected pieces.

Explanation is probably the most common method teachers use to help children understand how one goes about reading and writing. Unfortunately, explanations can get wordy and often require a specialized language. We tell children that a good summary includes "the most important ideas," but some children are left wondering how to tell which ideas are most important. Unfortunately, explanations are often unhelpful. Children can define the main idea, for instance, but they still cannot construct an adequate summary reflecting the important information in a text. Explaining a process is an improvement compared to simply assigning students work, but many children do not acquire useful strategies from explanations alone.

Demonstration is teacher talk about the mental activities that occur during the reading and writing processes. Demonstration usually involves modeling and explaining along with demonstrating the thinking that occurs while reading and writing. For instance, a teacher might compose a summary of an informational passage on an overhead projector in front of the class (Cunningham \& Allington, 2007).

The teacher provides a model of the writing process and, ultimately, a model of a written summary. The teacher might work from a map or a web following an explanation of the essential summary elements. A demonstration would occur as the teacher thinks aloud during the composing, making visible the thinking that assembles the information for the summary, puts it into words, and finally creates a readable summary of the information presented. Similarly, the teacher demonstrates the complex mental processes that readers engage in while reading when she talks children through a strategy for puzzling out an unfamiliar word while reading a story. For example, "I can try a couple of things: Read to the end of the sentence; look at the word and see if I know any other words that might help me figure it out; ask myself, 'What makes sense here?'; double-check what word makes sense against word structure; read the sentence using the word that makes sense and has the right letters." Demonstrating such thinking and how thinking shifts from incident to incident ("Here I can look at the picture to get a clue"; "I think the word will rhyme with name because it is spelled the same way"; and so on) gives children the chance to see that skillful strategy use is flexible and always requires thinking, not rote memory of rules. 
Children only infrequently encounter such demonstrations in most classrooms. Children who find learning to read difficult often see the teacher and other children reading and writing, serving as models, but they wonder, "How do they do it?" All children benefit from instruction, but some children need incredible amounts of careful, personal instruction, with clear and repeated demonstrations of how readers and writers go about reading and writing (Duffy, 2003; Harvey \& Goudvis, 2000). Left without adequate demonstrations, struggling readers are likely to continue trying to make sense out of lessons, but rarely will they accomplish this feat. Some of these children learn to score better on tests but never really learn to read and write.

If we are to teach all children to read and write, then models, explanations, and demonstrations of how we go about reading and writing will be essential elements of instructional programs. While some children may discover the effective strategies that proficient readers and writers use so easily and flexibly, other children require substantially more careful and personalized teaching to acquire the same strategies.

\section{CONCLUSION}

The use of models as learning aides has two primary benefits. First, models provide accurate and useful representations of knowledge that is needed when solving problems in some particular domain. Second, a model makes the process of understanding a domain of knowledge easier because it is a visual expression of the topic. Gage and Berliner found that students who study models before a lecture may recall as much as $57 \%$ more on questions concerning conceptual information than students who receive instruction without the advantage of seeing and discussing models. Alesandrini (1981) came to similar conclusions when he studied different pictorial-verbal strategies for learning.

\section{Recommendations}

We therefore recommend the application of modeling in teaching our students in schools due to the following benefits.

- Models provide an environment for interactive student engagement. Evidence from science education research shows that significant learning gains are achieved when students participate in interactive engagement activities. Thus, it is important that the learning environment/activity created around a model provide an interactive engagement experience.

- Working with models can enhance students systems thinking abilities

- Models and model development are useful for helping students learn quantitative skills such as graphing, graphical analysis, and visualization; statistics; computational skills, mathematics e.t.c

- Many models allow students to perform sensitivity studies to assess how changes in key system variables alter the system's dynamic behavior. Such sensitivity studies can help students identify leverage points of a system to either help one affect a desire change with a minimum effort or to help estimate the risks or benefits associated with proposed or accidental changes in a system. 
- Earth System Models such as those at Earth-System Models of Intermediate Complexity allow students to perform experiments related to the Earth System without altering and potentially harming the actual Earth. Many experiments, like understanding the future effects of atmospheric carbon dioxide increase, are taking place in the actual Earth System today but the results of these will not be know for 50 to 100 years. An Earth System model can run several such simulations using different assumptions in a matter of hours to days. The same is true for most models.

- The knowledge gained while using models and the understanding of model development and implementation are transferable to other disciplines related to the Earth system.

\section{References}

[1] Bandura A. (1986). Social foundations of thought and action: A social cognitive theory. Englewood Cliffs, NJ: Prentice-Hall.

[2] Bandura. In G. M. Gazda \& R. J. Corsini (Eds.), Theories of learning: A comparative approach (pp. 370-403). Itasca, IL: F. E. Peacock.

[3] Baldwin M., Keating J., Bachman K. (2006). Teaching in Secondary Schools: Meeting the Challenges of Today's Adolescents. Upper Saddle River, NJ: Pearson

[4] Collins A., Brown J. S., Holum,A. (1991). Cognitive apprenticeship: Making thinking visible. American Educator, 6(11), 38-46.

[5] Collins A., Brown J. S., Newman S. E. (1989). Cognitive apprenticeship: Teaching the crafts of reading, writing, and mathematics. In L. B. Resnick (Ed.), Knowing, learning, and instruction (pp. 453-494). Hillsdale, NJ: Erlbaum.

[6] Duncan S. L. S. (1996). Cognitive apprenticeship in classroom instruction: Implications for industrial and technical teacher education. Journal of Industrial Teacher Education, 33 ; 66-86.

[7] Duplass J. (2006). Middle and High School Teaching: Methods, Standards, and Best Practices. Boston: Houghton Mifflin Company. p. 204.

[8] Duplass J. (2006). p. 205.

[9] Duplass J. (2006). p. 204.

[10] Holland C. J., Kobasigawa A. (1980). Observational learning.

[11] John-Steiner V., Mahn H. (1996). Sociocultural contexts for teaching and learning. In D. C. Berliner \& R. C. Calfee (Eds.), Handbook of educational psychology (pp. 125-151). New York: Macmillan.

[12] Lefrancois G. R. (2000). Theories of human learning (4th ed.). Belmont, CA: Wadsworth/Thomson Learning.

[13] Masia C. L., Chase P. N. (1997). Vicarious learning revisited: A contemporary behavior analytic interpretation. Journal of Behavior Therapy \& Experimental Psychiatry, 28(1); 41-51. 
[14] Miller P. H. (1983). Theories of developmental psychology. San Francisco: W. H. Freeman.

[15] R. L. Allington, P. M. Cunningham (2010). Children Benefit from Modeling, Demonstration, and Explanation. Pearson Allyn Bacon Prentice Hall

[16] Schunk D. H., Zimmerman B. J. (1996). Self-regulation and learning. In D. C. Berliner \& R. C. Calfee (Eds.), Handbook of educational psychology (pp. 59-78). New York: Macmillan.

[17] Abdulrahaman W. Lawal, International Letters of Social and Humanistic Sciences 3 (2014) 53-59.

[18] Alaba E. Dare, International Letters of Social and Humanistic Sciences 3 (2014) 73-79.

[19] Grema Maina Bukar, Yohanna A. Timothy, International Letters of Social and Humanistic Sciences 4 (2014) 9-21.

[20] M. N. Modebelu, F. K. Igwebuike, International Letters of Social and Humanistic Sciences 4 (2014) 40-48.

[21] Akor Isaiah Akem, Victor Tavershima Ukeli, International Letters of Social and Humanistic Sciences 4 (2014) 49-59.

[22] Sule Maina, International Letters of Social and Humanistic Sciences 4 (2014) 87-96.

[23] Nwachukwu Uche Emma, International Letters of Social and Humanistic Sciences 5 (2014) 1-12.

[24] Peace Ebele Ilechukwu Chukwbikem, International Letters of Social and Humanistic Sciences 8(1) (2014) 1-17.

[25] Odo John Ogar, International Letters of Social and Humanistic Sciences 8(1) (2014) 28-33.

[26] Halima Sidi Bamall, International Letters of Social and Humanistic Sciences 8(1) (2014) 50-55.

[27] Elizabeth Morenikeji Titilayo Adediran, Albert Oluyomi Kehinde, International Letters of Social and Humanistic Sciences 8(1) (2014) 66-75.

[28] S. A. Kazeem, K. Y. Balogun, International Letters of Social and Humanistic Sciences 8(2) (2014) 108-119.

[29] Nneka Rita Udoye, Victor Etim Ndum, International Letters of Social and Humanistic Sciences 8(2) (2014) 130-139.

[30] Sanusi L. Sa'adatu, International Letters of Social and Humanistic Sciences 8(2) (2014) 140-147.

[31] Dennis Agama Eka, International Letters of Social and Humanistic Sciences 8(2) (2014) 170-182.

[32] Nayereh Shahmohammadi, International Letters of Social and Humanistic Sciences 8(2) (2014) 183-191.

[33] Godwin E. Itua, International Letters of Social and Humanistic Sciences 8(3) (2014) 200-207. 
[34] Rowland U. Aleshi, Clementina N. Iloh, International Letters of Social and Humanistic Sciences 8(3) (2014) 208-216.

[35] Hannatu Abdullahi, International Letters of Social and Humanistic Sciences 8(3) (2014) 217-223.

[36] Fowoyo Joseph Taiwo, International Letters of Social and Humanistic Sciences 8(3) (2014) 244-251. 